\title{
Regenerated Cellulose-Based Denim Fabric for Tropical Regions: An Analytical Study on Making Denim Comfortable
}

\author{
Annu Kumari and Karan Khurana \\ Ethiopian Institute of Textile and Fashion Technology, Bahir Dar University, Bahir Dar, Ethiopia \\ Correspondence should be addressed to Annu Kumari; ajatyan48@gmail.com
}

Received 21 October 2015; Accepted 1 February 2016

Academic Editor: Anindya Ghosh

Copyright ( 2016 A. Kumari and K. Khurana. This is an open access article distributed under the Creative Commons Attribution License, which permits unrestricted use, distribution, and reproduction in any medium, provided the original work is properly cited.

\begin{abstract}
Denim is no more "work wear" in the present era. More than a need, it is a fashion commodity for every age group, specifically for youth. Garments with multiple permutations and combinations of denim fabric variables like fibers, yarns, and Lycra \% and weaving techniques are available with differing garment design statements, but the comfort aspect is slightly ignored. To cater for the masses living in hot and humid areas, a denim fabric is being projected with varying garment constructional parameters. Regenerated cellulose-based fibers/yarns are considered as ecofriendly, cool, soft, fairly strong, and durable among other man-made and natural fiber-based yarns. The present study is an attempt to develop comfortable denim clothing using regenerated cellulose fiber derivatives, maintaining its traditional rustic look for tropical regions. Fabric performance evaluation methods were used to ascertain the performance of the newly developed clothing.
\end{abstract}

\section{Introduction}

Denim has now clearly established itself as the definitive "street wear" fabric and has wide age and socioeconomic appeal. Denim mills are now, more than at any time previously, spending large amounts of money in developing new concepts in denim, which in turn means that all jeans manufacturers will experiment with and achieve new levels of finishing [1]. The product has been conventionally made with $100 \%$ cotton since inception. Denim is the unique apparel preferred by all age groups and due to its popularity, a lot of development work has been done in the last few decades. Due to these innovations, a large number of variants of denim are available to the customer today. The expectations from fabrics have changed with developments in textile technology and the consumers' living standards. Modern consumers are interested in clothing that not only looks good but also feels great. Studies have shown the importance of clothing comfort in deciding customer satisfaction. Now the requirement from a garment is not only style and durability, but also clothing comfort. Clothing that is in direct contact with the human body interacts continuously and dynamically with the skin during use. Such interaction between clothing and the human body stimulates mechanical, visual, and thermal sensations, which eventually lead to perception of either comfort or discomfort. Slater has defined clothing comfort as a pleasant state of physiological, psychological, and physical harmony between the human being and the environment [2]. Clothing comfort includes three main considerations: psychological, sensorial, and thermophysiological comfort. It is known that fiber type, yarn properties, fabric structure, finishing treatments, and clothing conditions are the main factors affecting thermophysiological comfort. Sensations that arise from the thermal and moisture transport properties of clothing are important inputs to the perception of state of comfort. An understanding of fabric properties that influence thermal and moisture sensations is essential for engineering fabrics that provide maximum comfort to the wearer. While innovations have been made to offer new colors and different look and feel of the denim fabric, not much work is reported to have been done to add comfort to this all-time favorite apparel. Keeping the abovementioned facts in view this concept "regenerated cellulose-based denim" aims at providing mankind with great comfortable denim trousers. The proposed project aims at studying the comfort aspects of the denim followed by development of a new comfortable product using different types 
of regenerated fibers with cotton but maintaining the original rugged and rustic look of denim. The research work envisages not only offering more comfortable denim but also providing an alternative to cotton which is already in short supply due to enormous global demand. Regenerated fibers are produced from natural origin such as wood pulp. These cellulosic fibers have high tensile strength, bright look, and soft feel. These are resistant to wear and have smooth handle. These products can transfer moisture well and provide wearing comfort in hot, moist climatic conditions besides being comfortable in moderate conditions as well.

\section{Materials and Methods}

In this research work, different fabric is developed with using regenerated cellulose and its derivatives like modal, Tencel, and bamboo yarns in weft way of the fabric to impart cool sensation. Viscose filament was also used to give lustrous look to fabric and to make product comfortable and trendier. All yarns used were ring yarns with $2 / 30$ s count in both warp and weft direction. All fabric samples with 3/1 twill weave were prepared in GBTL (Grasim Birla Textile Ltd.) Fabric Mills, Bhiwani (Haryana), and these samples were processed in their processing unit and were subjected to scouring at $60^{\circ} \mathrm{C}-70^{\circ} \mathrm{C}$ with DTC soap in jigger machine and dried in Stenter at $160^{\circ} \mathrm{C}$. Different fiber, yarn, fabric, and machine parameters are stated in Tables 1 and 2.

\section{Testing Procedure}

All usual tests for yarn and fabrics were done like linear density (yarn and fabric), strength (yarn and fabric), flexural rigidity, air permeability, MVTR, and so forth. Some specific tests were carried out to check cool and comfortable sensation of the fabric. These are described as below.

3.1. Alambeta. Alambeta, a test instrument, has been developed at the Technical University of Liberec in Czech Republic for assessing thermal absorptivity of textile fabrics. It is computer-controlled. It calculates the thermal absorptivity $\left(\mathrm{Ws}^{1 / 2} / \mathrm{m}^{2} \mathrm{~K}\right)$ by using the statistical parameters of measurements for thermophysiological properties like thermal conductivity, thermal resistance, maximum level of heat flux, and sample thickness.

The first sensation experienced by a human being while touching a fabric is a "warm-cool" feeling as a result of heat exchange that takes place, owing to the temperature difference between the fabric surface and the human skin [3]. Alambeta is helpful in identifying warm/cool behavior of the fabric.

3.2. Textest Instrument. Textest FX 3300 instrument was used to measure air permeability of the samples $\left(\mathrm{cm}^{3} / \mathrm{cm}^{2} / \mathrm{S}^{-1}\right)$ via standard TS 391 EN ISO 9237 method. The measurements were performed at a constant pressure drop of $98 \mathrm{~Pa}\left(20 \mathrm{~cm}^{2}\right)$ test area [4-6]:

$$
\text { Number of samples observed }=10 \text { samples. }
$$

3.3. Moisture Vapour Transmission Rate Cell. The Grace, Cryovac Division, has developed a Moisture Vapour Transmission Cell (MVTR Cell), which offers a faster and more simplified method for measuring the water vapour transmission behavior of a fabric. In principle, the cell measures the humidity generated under controlled conditions as a function of time [6]:

$$
T=269 * 10^{-7}\left(\frac{\Delta \% \mathrm{RH} \times 1440}{\text { time interval }}\right) \mathrm{g} \mathrm{in}^{-2} \text { day }^{-1} .
$$

This is based on the application of the gas permeability equation and ideal gas law. The gas permeability equation states that the "mass transfer rate is proportional to the permeability of the barrier; the pressure differential across the barrier and the reciprocal of the barrier thickness." The form of the ideal gas law states that the "rate of mass change (or the differential change of mass with respect to pressure) is proportional to the total volume and the reciprocal of the product of the universal gas constant and temperature." Average the cell temperature readings and determine actual temperature for each cell from proper calibration curve. From the proper calibration curve, determine the \% relative humidity $(\% \mathrm{RH})$ value that corresponds to each dial reading at the actual cell temperature. Then calculate the average difference in successive \% $\mathrm{RH}$ values; then average these differences:

$$
T=\left(269 \times 10^{-7}\right)\left(\frac{\Delta \% \mathrm{RH} \times 1440}{\text { time interval }}\right)(H),
$$

where $\mathrm{H}$ is $\mathrm{H}_{2} \mathrm{O} / \mathrm{m}^{3}$ of air at cell temperature.

3.4. Kawabata Instrument. The fabric samples were tested at the Indian Institute of Technology, Delhi, India. The tensile and shear properties were studied on KES-FB1 (tensile and shear tester). The tensile properties were measured by plotting the force extension curve between zero and a maximum force used of $500 \mathrm{gf} / \mathrm{cm}$ and the recovery curve. Shear properties were measured by shearing a fabric sample parallel to its long axis, by keeping a constant tension of $10 \mathrm{gf} / \mathrm{cm}$ on the clamp. Bending properties were measured on KES-FB2 (pure bending tester) by bending the fabric sample between the curvatures -2.5 and $2.5 \mathrm{~cm}^{-1}$.

KES-FB3 (compression tester) was used to calculate compression properties, by placing the sample between plates and increasing the pressure while continuously monitoring the sample thickness to a maximum pressure of $50 \mathrm{gf} / \mathrm{cm}^{2}$. the total hand values were calculated from the sixteen mechanical properties using the prescribed procedure by Kawabata and Niwa, as shown in Figure 7.

\section{Results and Discussions}

As all fibers were cellulose-based, ANOVA analysis was used to identify the statistically significant difference $(P \leq 0.001)$ between samples to check the authenticity of the results.

4.1. Thermophysiological Properties. Thermophysiological properties include thermal absorptivity, thermal resistance, 


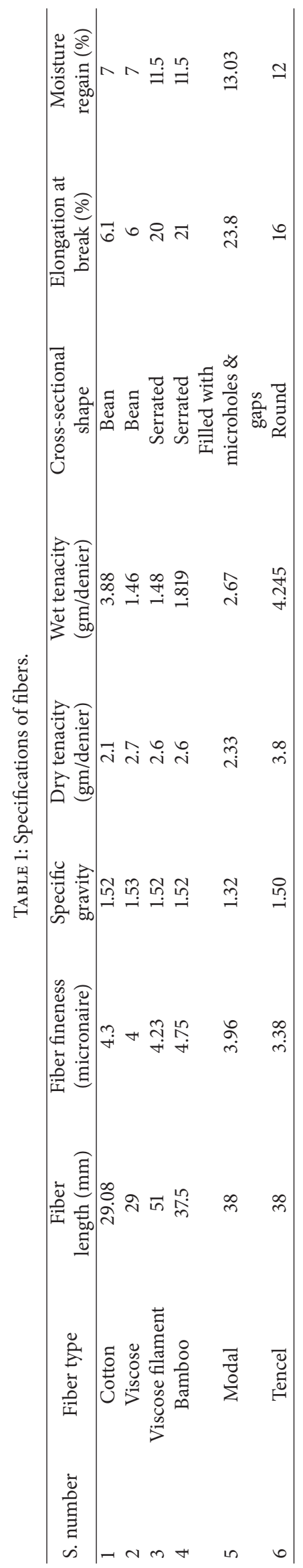




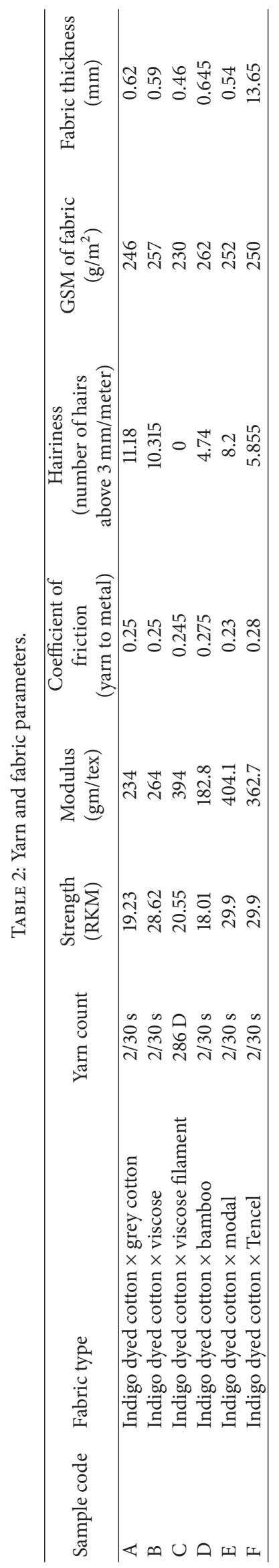


TABLE 3: Thermophysiological properties.

\begin{tabular}{|c|c|c|c|c|}
\hline Fabric code & Thermal absorptivity $\left(\mathrm{Ws}^{1 / 2} / \mathrm{m}^{2} \mathrm{~K}\right)$ & Heat conductivity $(\mathrm{W} / \mathrm{mK})$ & Heat resistance $\left(\mathrm{m}^{2} \mathrm{~K} / \mathrm{W}\right)$ & $q_{\max }$ \\
\hline A & 98.671 & 29.41 & 21.17 & 0.343 \\
\hline B & 102.2 & 28.31 & 21 & 0.358 \\
\hline $\mathrm{C}$ & 106.32 & 25.97 & 17.87 & 0.373 \\
\hline $\mathrm{D}$ & 99.2 & 29.78 & 21.67 & 0.34 \\
\hline $\mathrm{E}$ & 107.91 & 28.52 & 19 & 0.372 \\
\hline $\mathrm{F}$ & 88.67 & 27.18 & 20.85 & 0.334 \\
\hline
\end{tabular}

and heat conductivity. A warm/cool feeling is the first sensation; when a human touches a garment that has a different temperature than the skin, heat exchange occurs between the hand and the fabric [7]. Thermal absorptivity is a transient phenomenon of heat flow which reflects that the warm/cool feeling effect of fabric depends upon the smoothness/roughness of the fabric surface. Fabrics with smooth surfaces have higher thermal absorptivity values as they provide a large area of contact with human skin. Fabrics with rough surfaces decrease surface contact; hence this results in a decrease in thermal absorptivity value [8]. In case of sample $\mathrm{C}$, absorptivity value is the highest among all, showing its cool sensation. (The contact feeling is warmer.) The thermal resistance $(R)$ is associated with the fabric structure and is a very important parameter governing thermal insulation $[9,10]$. It is a measure of a material ability to prevent heat from flowing through it. Under certain climatic conditions, if the thermal resistance of clothing is low, heat energy will tend to gradually decrease, giving rise to a cool feeling. Increase in fabric thickness will result in increase in thermal resistance. It is observed that samples A and $C$ found intermediate values of thermal resistance and sample D has seen the highest value of thermal resistance [11]. Conductivity is an intrinsic property of a material, that is, ability to conduct heat. The thermal conductivity of fabrics is highly influenced by the presence of air rather than fibers and their thermal resistance largely depends on the fabric thickness and conductivity [12]. This property of fabric represents warm/cool feeling of fabric. The higher the value is, the cooler the feeling that it represents is. It is predicted that the heat conductivity is highest in case of sample $\mathrm{D}$ due to its lower value of hairiness as well as porous structure microholes and pores. Sample $\mathrm{C}$ shows the lowest value of heat conductivity due to its morphological structure $[13,14]$. In case of other fabrics values are intermediate for heat conductivity and are greatly influenced by fabric structure as shown in Table 3.

Maximum Level of Contact Heat Flux $\left(q_{\max }\right)$. The rate of heat flow, which reaches a peak value $\left(q_{\max }\right)$ approximately $0.2 \mathrm{sec}$ after contact with the fabric, is related to the warm/cool feeling felt by the wearer. It was found that sample $C$ was the finest among all spun fibers so it shows the highest $q_{\max }$ value. An increase in geometrical roughness (SMD) implies an increase in the roughness of the surface of the fabric. When the contact between skin simulating heat source and fabric is reduced by an irregular fabric surface contour, this will result in the lowering of $q_{\max }$ value in case of sample D.

It was observed that the other types of fabrics gave in between values of maximum level of contact heat flux.

4.2. Air Permeability. Air permeability indicates ability of the fabric to allow atmospheric air to be in contact with user skin and passage of water vapour (perspiration) to move out into the atmosphere. Sample A gave the lowest value among all, which may be due to more yarn hairiness and cover factor. The more the cover factor is, the lesser the air permeability will be and vice versa. The comfort or cool feel of the fabric will increase by increase in air-permeability value. It was found that the highest value is in case of sample $\mathrm{C}$ among all due to its high fiber fineness and less hairiness and provides the best cool feel as compared to other fabrics.

Moisture Vapour Transmission. As the viscose proportion in the fabric will increase, moisture regain of the material will be increased causing higher diffusivity. In the same way moisture transfer through sorption-desorption process will increase with the hygroscopicity of the material. A hygroscopic fabric absorbs water vapour from the humid air close to the sweating skin and releases it in dry air. This enhances the flow of water vapour from the skin to the environment comparatively to a fabric which does not absorb vapour and reduces the moisture built up in the microclimate, whereas the fabric with less hygroscopicity will provide higher resistance to the water vapour transfer $[12,15,16]$. Since the moisture regain of sample B gave the highest value, it provides comfort to the user.

Comfort Properties. Denims are mostly composed of twilled weave fabrics, having filling yarns floating across the warp and a higher pick density and a bigger number of floating yarns on the fabric surface. These floating weft yarns help to impart better thermal contact between the skin and the fabrics surface and the influence of warp yarns that do not come in contact with the skin is minimal. Hence, weft yarns predominantly influence the heat exchange between skin and the fabric. So, to carry out comfort evaluation of different fabric types weftwise direction of fabrics was considered and shown in Table 5.

EMT has a good correlation with fabric handle. So, the higher the extensibility, the better the fabric quality from the handle point of view. A high EM value also indicates greater 


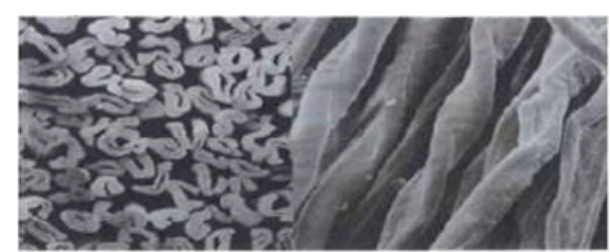

FIGURE 1: Cross-sectional/longitudinal view of cotton.

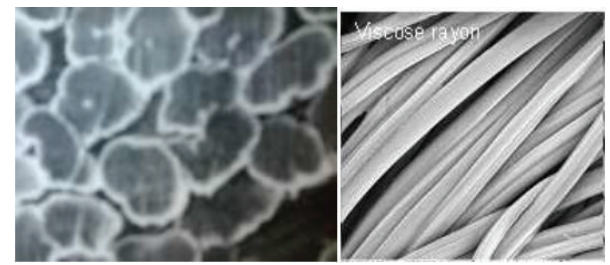

FIgURE 2: Cross-sectional/longitudinal view of viscose.

wearing comfort. Tensile linearity signifies the uniformity in tensile load-bearing capacity [17]. Sample C shows the highest value of linearity as compared to other fabrics due to uniform yarn structure. Low tensile energy causes low extension at low stress level. Resilience represents recovery from tensile deformation. The higher the tensile resilience of a fabric, the better its fabric handle. The result also shows that the ability to recover from tensile deformation is highest in case of sample C compared to other types of fabrics.

Bending rigidity is a measure of ease with which fabric bends. Bending rigidity of fabric depends on the bending rigidity of constituent fiber and yarns from which the fabric is manufactured.

The shear rigidity of a fabric depends on the mobility of cross threads at the intersection point, which depends on the weave, yarn diameter, and the surface characteristics of both fiber and yarn. In comparative graphs of bending rigidity and shear rigidity of different samples, as shown in Figures 4 and 5 , shear rigidity is the highest in case of sample $\mathrm{C}$ among all. From the point of view of handle, the lower the shear rigidity is, the better the fabric handle would be. So hand value is lowest in case of viscose filament cotton-based fabric. Other cellulosic fabrics show intermediate values of shear behavior.

The handle, comfort, and aesthetic properties of the cloth are influenced by the surface characteristics of fabric, yarn, and fiber. SEM of fiber surface morphology is shown in Figures 1, 2, and 3. Bamboo and viscose fiber surfaces show lots of serrations. MMD is the mean deviation of the MIU, or it is the measure of variation of MIU. The geometrical roughness of fabric is represented by SMD (Figure 6).

Compressibility contributes to a feeling of bulkiness and spongy property in the fabric. The compressibility of a fabric mainly depends on yarn packing density and yarn spacing in the fabric. During fabric compression, initially the protruding fibers get compressed in the fabric surface, secondly the yarn gets compressed by the movement of constituent fibers, and finally the fiber gets compressed and its cross-sectional shape changed. Higher value of linearity in compression is the indication of hard feeling in material. Sample B has

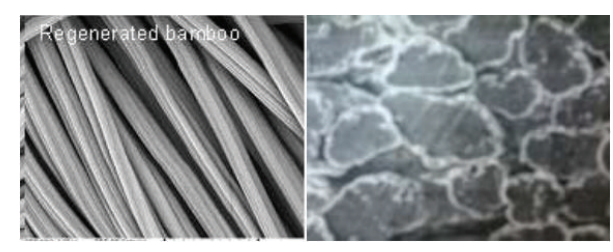

FIgURE 3: Cross-sectional/longitudinal view of bamboo fiber.

TABLE 4: Mean values of men's summer suiting.

\begin{tabular}{lccccc}
\hline S. number & Fabric type & Koshi & Shari & Fukurami & Hari \\
\hline 1 & A & 7.30 & 2.58 & 8.38 & 8.26 \\
2 & B & 6.96 & 2.94 & 8.58 & 8.25 \\
3 & C & 8.41 & 5.28 & 7.94 & 9.10 \\
4 & D & 6.68 & 1.92 & 8.65 & 7.91 \\
5 & E & 7.28 & 2 & 8.54 & 8.81 \\
6 & F & 6.81 & 2.51 & 8.75 & 8.16 \\
\hline
\end{tabular}

exhibited slightly higher WC which may be attributed due to the lower packing density and higher hairiness than bamboo and viscose yarn. Compressibility also relates with primary hand values (Fukurami and fullness) of the fabric. The reason for higher value of compressional energy in case of sample B was due to the noncircular cross-sectional shape (Figure 2) which was also playing a positive role in enhancing WC.

Koshi represents stiffness of the fabric and contributes $30 \%$ among all PHV towards coolness of the fabric. Shari represents crispness of the fabric. The higher the value of shari is, the cooler the fabric will be. Shari contributes 35\% among THV of the fabric. Here again sample $C$ shows the highest shari value among all. Hari represents the fabric hardness, boardiness, and antidrape stiffness of fabric. Cotton $\times$ bamboo fabric was given the lowest value of hari, that is, 7.91. Hari is $10 \%$ contributor towards cool feel of the fabric. So, sample C showed more cool sensation.

Total Hand Values. Total hand value of six types of men's summer suiting samples is shown in Table 4 . The THV of the fabric was estimated with the help of various primary hand values using the Kawabata-Niwa equations by KES system. The fiber macro- and microscopic fine structure influences fabric handle and its suitability to winter and summer applications. Sample C exhibited good THV compared to cotton; this may be due to noncircular fiber structure, lower value of hairiness, and higher moisture regain of the viscose fiber. Samples B, A, F, D, and E were showing gradually decreasing THV. So, sample C is coolest among all fabric types.

\section{Conclusion}

This research shows that cellulosic derivatives like modal, bamboo, and Tencel yarns have different properties due to their manufacturing techniques and raw material, but no significant effect on end product. Cellulosic content determines the moisture $\%$ within the fiber, resulting in cooling sensation 


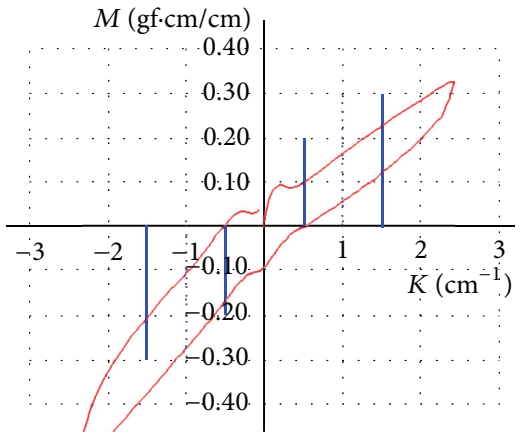

Cotton

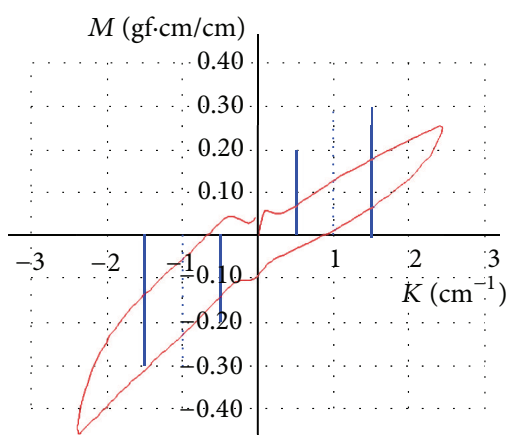

Bamboo

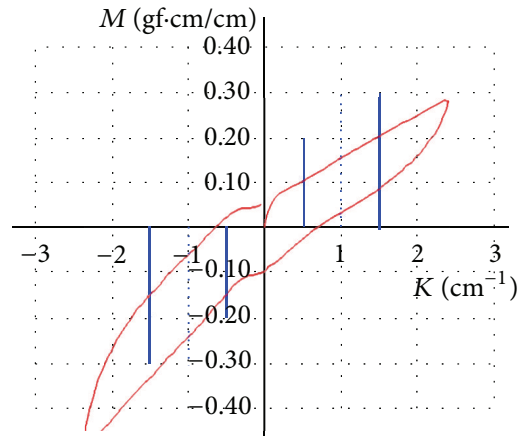

Viscose

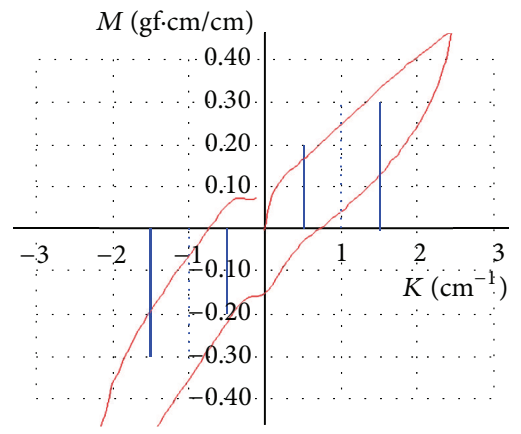

Modal

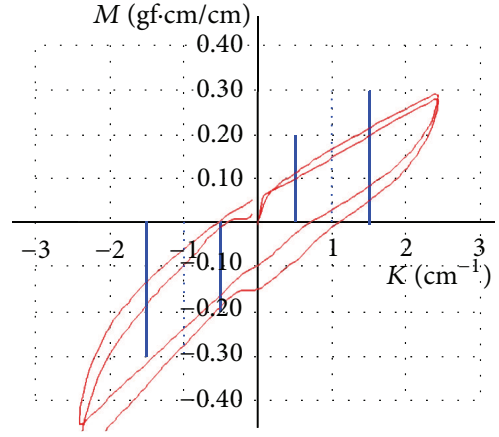

Viscose filament

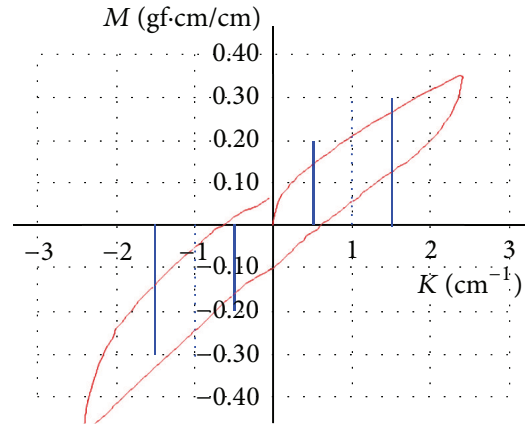

Tencel

FIGURE 4: KES-F graphs for bending of different fabric samples.
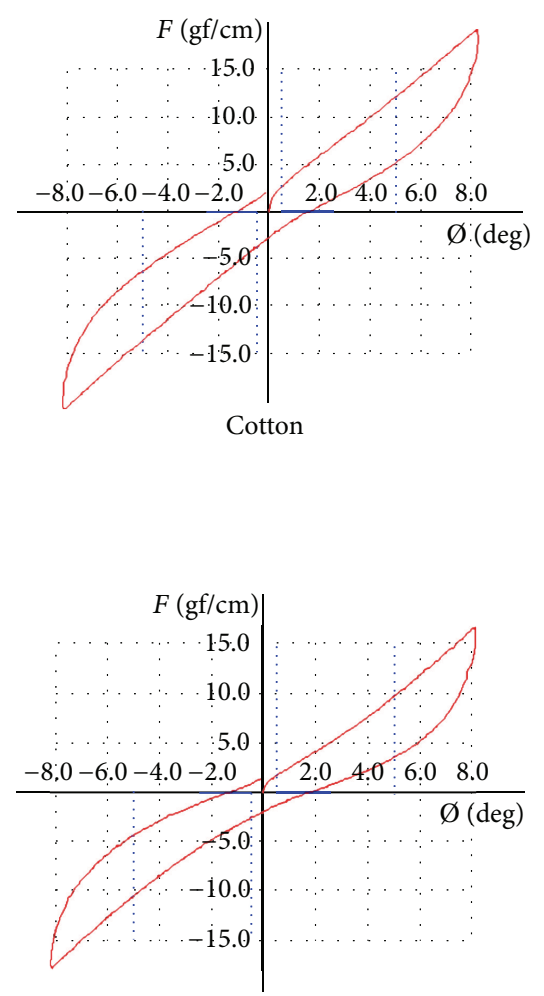

Bamboo
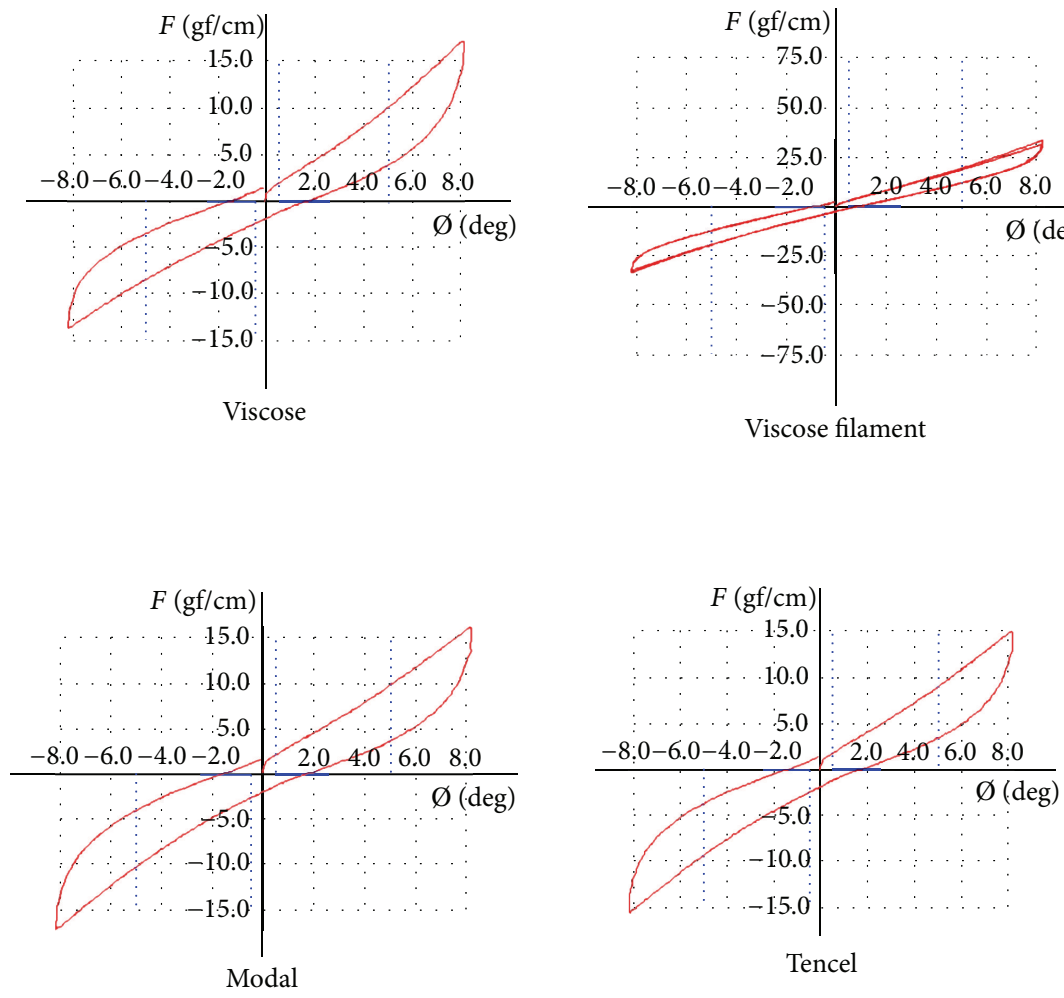

Tencel

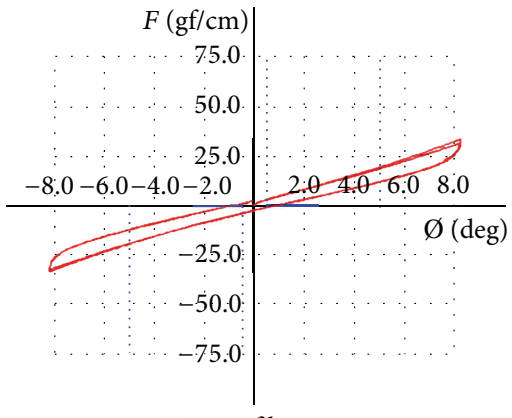

Viscose filament

FIGURE 5: KES-F graphs for shear property. 

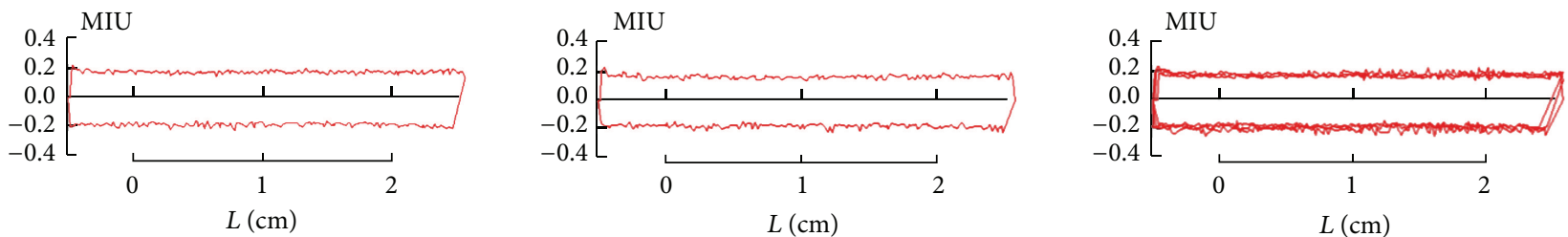

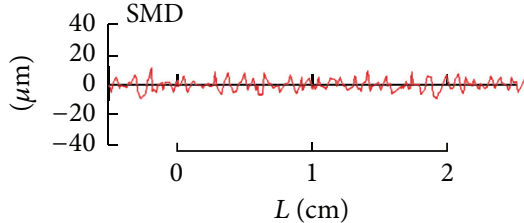

Cotton

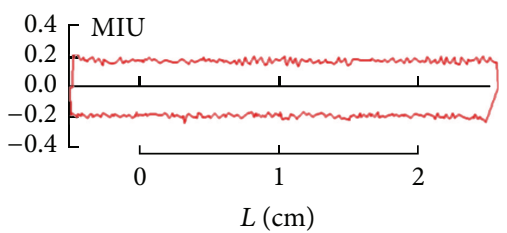

E $\begin{array}{r}40 \\ 20 \\ 0 \\ -20 \\ -40\end{array} \mid \begin{array}{cc}1 \\ 0 \\ L(\mathrm{~cm})\end{array}$

Bamboo

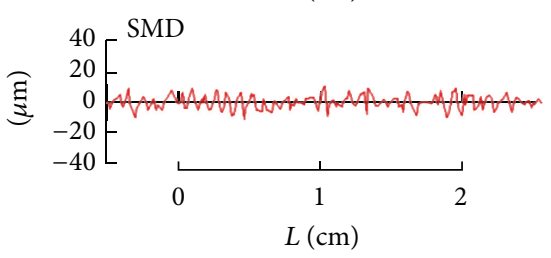

Viscose
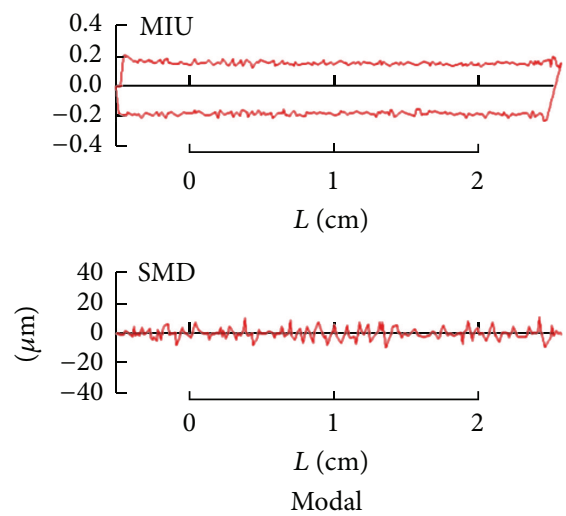

FIGURE 6: KES-F graphs for surface characteristics.

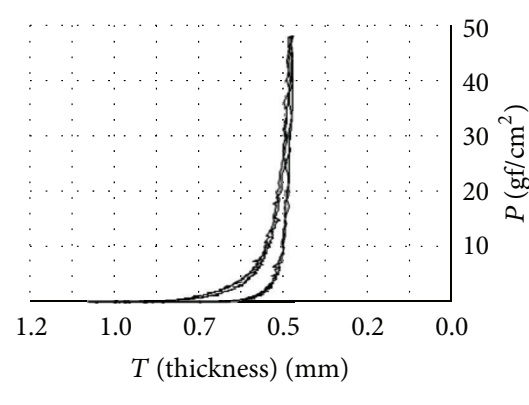

Cotton
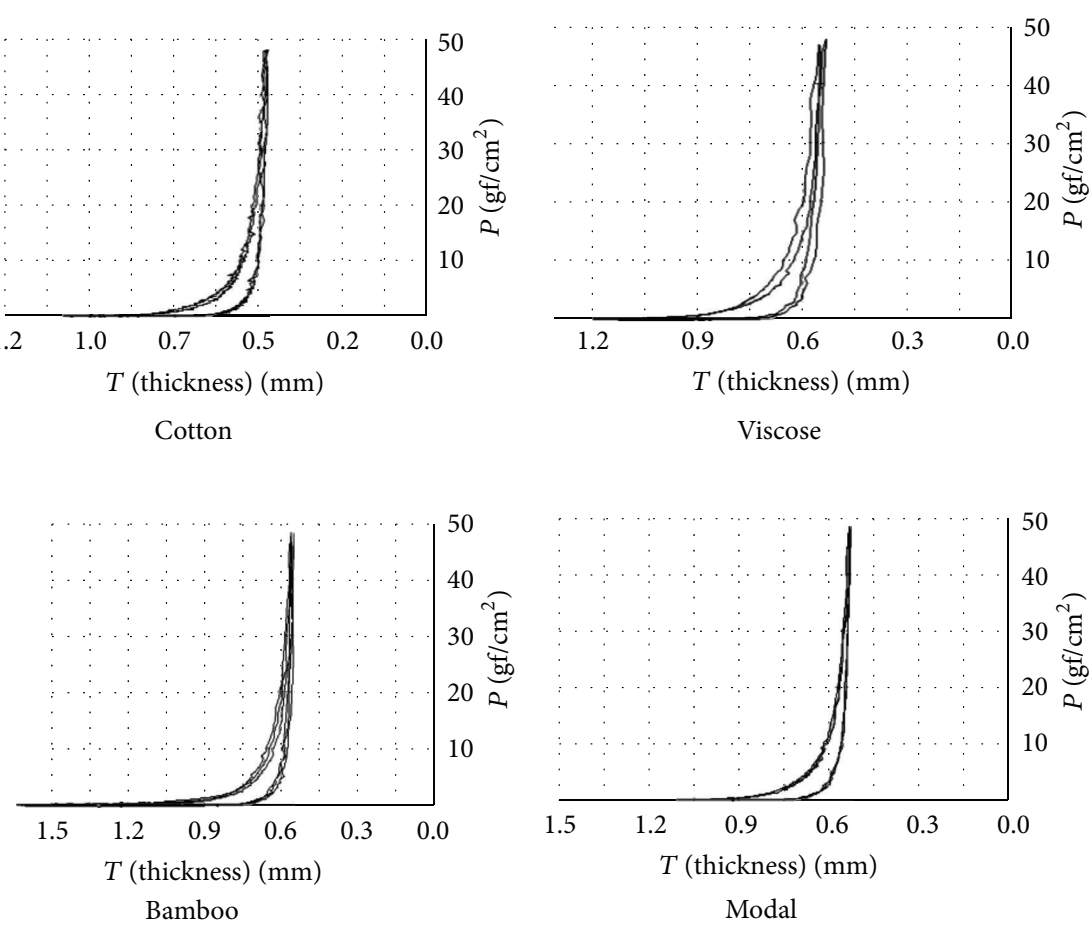

Viscose

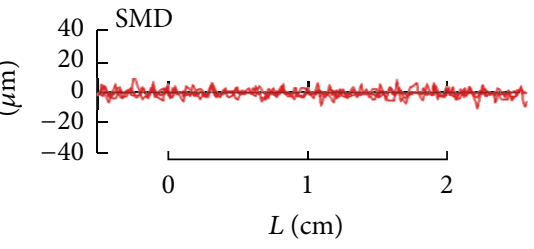

Viscose filament
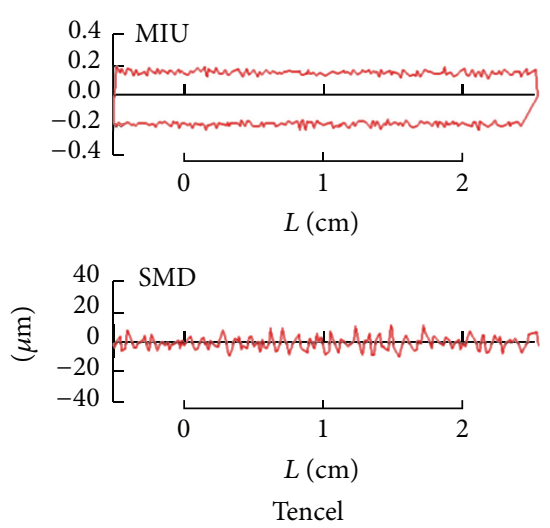

Tencel 
TABLE 5: Primary hand values.

\begin{tabular}{|c|c|c|c|c|c|c|c|c|}
\hline S. number & Property & Unit & A & $\mathrm{B}$ & $\mathrm{C}$ & $\mathrm{D}$ & $\mathrm{E}$ & $\mathrm{F}$ \\
\hline 1 & Extensibility $(E M T)$ & $\%$ & 5.515 & 5.735 & 4.695 & 5.135 & 4.710 & 5.455 \\
\hline 2 & Linearity of load-extension curve ( $L T)$ & - & 0.712 & 0.655 & 0.780 & 0.676 & 0.720 & 0.657 \\
\hline 3 & Tensile energy $(W T)$ & $\mathrm{gf} \cdot \mathrm{cm} / \mathrm{cm}^{2}$ & 0.825 & 9.400 & 8.975 & 8.675 & 0.475 & 8.950 \\
\hline 4 & Tensile resilience $(R T)$ & $\%$ & 54.100 & 52.390 & 65.975 & 52.450 & 47.790 & 55.890 \\
\hline 5 & Bending rigidity $(B)$ & $\mathrm{gf} \cdot \mathrm{cm}^{2} / \mathrm{cm}$ & 0.172 & 0.144 & 0.227 & 0.147 & 0.207 & 0.148 \\
\hline 6 & Hysteresis of bending moment $(2 \mathrm{HB})$ & $\mathrm{gf} \cdot \mathrm{cm} / \mathrm{cm}$ & 0.139 & 0.142 & 0.105 & 0.141 & 0.214 & 0.159 \\
\hline 7 & Shear stiffness $(G)$ & $\mathrm{gf} / \mathrm{cm} /$ degree & 2.180 & 1.538 & 3.398 & 1.613 & 1.538 & 1.500 \\
\hline 8 & Hysteresis of shear force at $0.5 \mathrm{deg}$ of shear angle $(2 \mathrm{HG})$ & $\mathrm{gf} / \mathrm{cm}$ & 5.012 & 3.575 & 4.975 & 3.513 & 3.575 & 3.425 \\
\hline 9 & Hysteresis of shear force at 5 deg of shear angle (2HG5) & $\mathrm{gf} / \mathrm{cm}$ & 7.412 & 5.938 & 7.400 & 6.412 & 5.938 & 5.763 \\
\hline 10 & Coefficient of friction $(M I U)$ & - & 1.765 & 1.582 & 1.773 & 1.788 & 1.665 & 1.688 \\
\hline 11 & Mean deviation of $M I U(M M D)$ & - & 0.715 & 3.992 & 0.948 & 0.715 & 0.887 & 1.070 \\
\hline 12 & Geometrical roughness (SMD) & $\mu \mathrm{m}$ & 3.673 & 6.493 & 2.177 & 3.462 & 3.103 & 3.618 \\
\hline 13 & Linearity of compression $(L C)$ & - & 0.336 & 0.306 & 0.269 & 0.255 & 0.290 & 0.295 \\
\hline 14 & Compression energy $(W C)$ & $\mathrm{gf} \cdot \mathrm{cm} / \mathrm{cm}^{2}$ & 0.412 & 0.293 & 0.233 & 0.307 & 0.260 & 0.277 \\
\hline 15 & Compression resilience $(R C)$ & $\%$ & 31.247 & 33.273 & 34.810 & 29.483 & 36.233 & 33.943 \\
\hline 16 & Thickness $(T)$ & $\mathrm{mm}$ & 1.066 & 1.188 & 0.801 & 1.040 & 0.887 & 0.973 \\
\hline 17 & Weight $(W)$ & $\mathrm{mg} / \mathrm{cm}^{2}$ & 104 & 109.32 & 93.89 & 107.77 & 104 & 104.89 \\
\hline
\end{tabular}

while touching to the human body. Decrease in yarn fineness and hairiness will improve the clothing comfort by providing more area of conduct of fabric to the wearer. Smooth and soft surfaced fabrics will add on soothing sensation to clothing for tropical regions. Thermophysiological properties depend upon ability to conduct heat and contact area of fabric with the body; therefore in case of filament fabric it is showing most favorable values. Air permeability is a measure of passage of air through the fabric that implies comfort of the clothing with less cover factor.

Kawabata evaluation is helpful to determine comfort behavior of fabrics by objective evaluation by doing tensile, bending, shear, compression, and surface properties evaluation. The cumulative results will give PHV (primary hand values) and THV (total hand values). PHV like koshi, shari, and hari were highest in case of sample C. Samples E, A, B, $\mathrm{F}$, and D were showing gradually decreasing PHV. Fukurami shows fullness, bulkiness of fabrics which is highest in case of samples D and B. Hence, samples C and F showed the largest value and contributing towards the comfortability in summer suiting.

\section{Competing Interests}

The authors declare that there are no competing interests regarding the publication of this paper.

\section{References}

[1] P. Roshan, N. R. Sandeep, and T. Jegadeesh, Denim: The Evergreen Favorite, Textile Dyer \& Printer, 1996.

[2] M. V. Vivekanadana, S. Raj, S. Suffixeenivasan, and R. P. Nachane, "Parameters affecting warm-cool feeling in cotton denim fabrics," Indian Journal of Fibre \& Textile Research, vol. 36, no. 2, pp. 117-121, 2011.
[3] S. Sengupta, "Electrical resistance of jute fabrics," Indian Journal of Fiber Textile Research, vol. 3, pp. 55-59, 2012.

[4] http://www.uni.edu/csbs/sites/default/files/Air_Permeability.pdf.

[5] A. Hladnik, K. Dimitrovski, and Z. Zupin, "Predicyion of onelayer woven fabrics air permeability using porosity parameters," Textile Research Journal, vol. 82, no. 2, pp. 117-128, 2012.

[6] S. Mavruz and R. T. Ogulata, "Investigation of air permeability of single jersey fabrics with different relaxation states," The Journal of the Textile Institute, vol. 102, no. 1, pp. 57-64, 2011.

[7] L. Hes, Thermal Properties of Nonwovens, vol. 87 of Proceedings of Congress Index, Geneva, Switzerland, 1987.

[8] G. Özçelik, A. Çay, and E. Kirtay, "A study of the thermal properties of textured knitted fabrics," Fibres and Textiles in Eastern Europe, vol. 15, no. 1, pp. 55-58, 2007.

[9] D. Romeli, G. Barigozzi, S. Esposito, G. Rosace, and G. Salesi, "High sensitivity measurements of thermal properties of textile fabrics," Polymer Testing, vol. 32, no. 6, pp. 1029-1036, 2013.

[10] R. Das, D. Battacharjee, and K. Kumar, "Thermo physiological comfort characterstics of Fine-denier Polypropylene fabrics," Research Journal of Textile and Apparel, vol. 17, no. 1, pp. 137139, 2013.

[11] Q. Huanxiong, Z. Yuan, W. Zhongevei, L. Jianli, L. Min, and Z. Jie, "Comfort in knitted fabrics," in Proceedings of the International Man-Made Fibers Congress, p. 112, Dornbirn, Austria, 1991.

[12] B. Das, A. Das, V. K. Kothari, R. Fangueiro, and M. de Araújo, "Studies on moisture transmission properties of PV-blended fabrics," Journal of the Textile Institute, vol. 100, no. 7, pp. 588597, 2009.

[13] P. Chidambaram, R. Govindan, and K. C. Venkatraman, "Study of thermal comfort properties of cotton/regenerated bamboo knitted fabrics," African Journal of Basic \& Applied Sciences, vol. 4, no. 2, pp. 60-66, 2012.

[14] M. Kandhavadivu, "Comfort and thermophysiogical characteristics of multilayered fabrics for medical textiles," Journal of Textile and Apparel Technology and Management, vol. 7, no. 1, pp. 45-47, 2011. 
[15] D. H. Morton and J. W. S. Hearle, Physical Properties of Textile Fibers, The Textile Institute, 1993.

[16] N. A. H. Ahmed and G. A. El-Kholy, "Effect of number of fibers per yarn cross-section on moisture vapour transport in knitted garment," Journal of American Science, vol. 8, pp. 370-378, 2012.

[17] S. Raj and S. Sreenivasan, "Total wear comfort index as an objective parameter for characterization of overall wearability of cotton fabrics," Journal of Engineered Fibers and Fabrics, vol. 4, no. 4, pp. 29-41, 2009. 

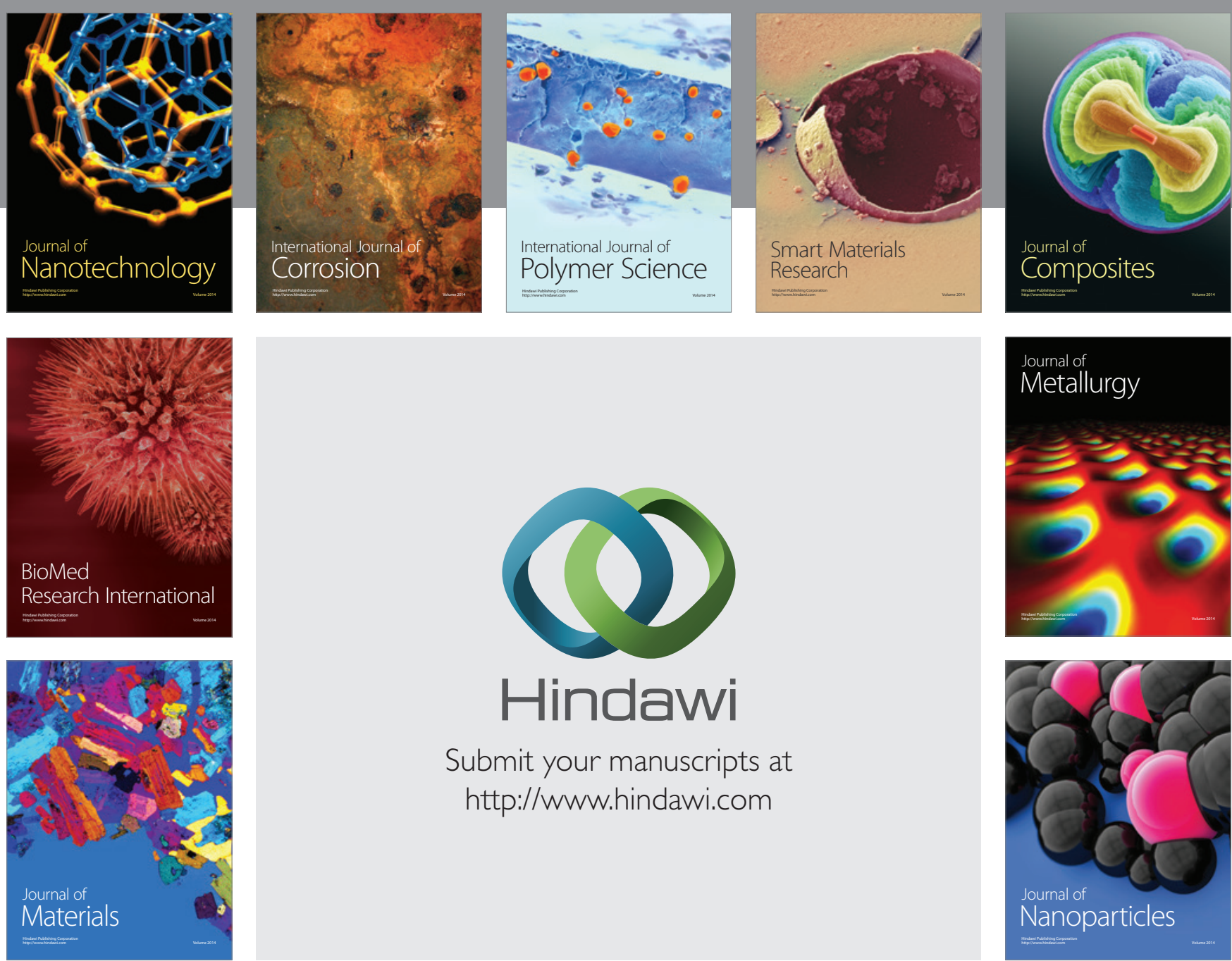

\section{Hindawi}

Submit your manuscripts at

http://www.hindawi.com

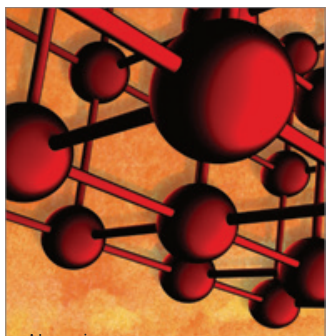

Materials Science and Engineering
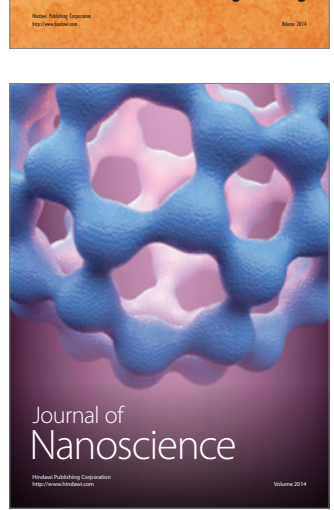
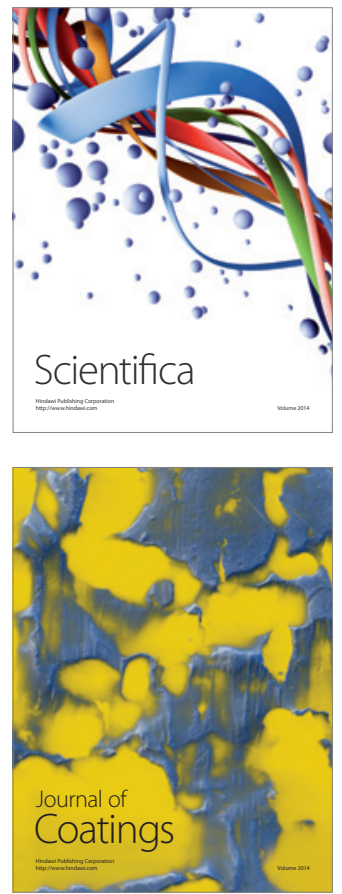
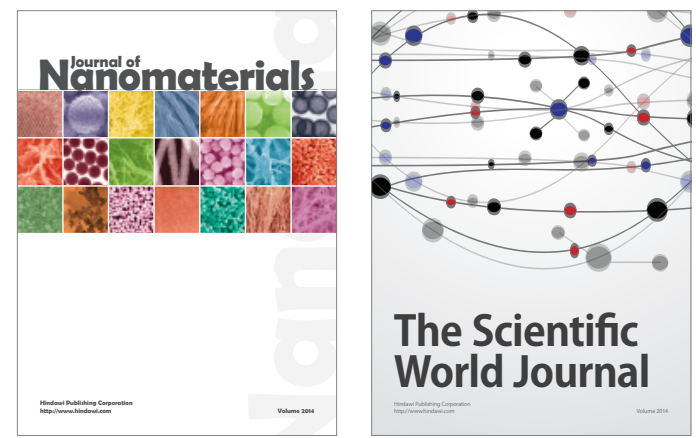

The Scientific World Journal
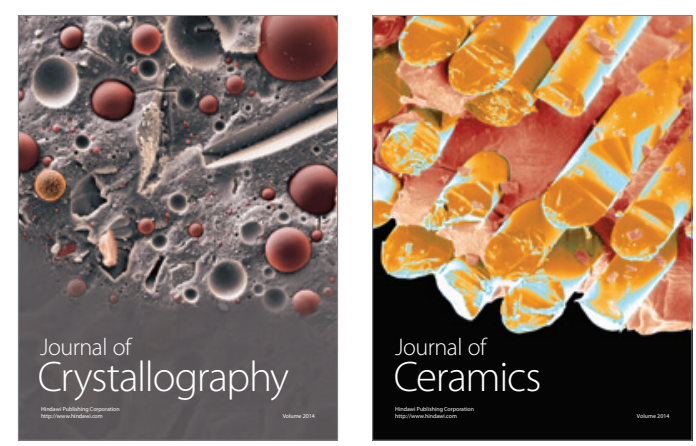
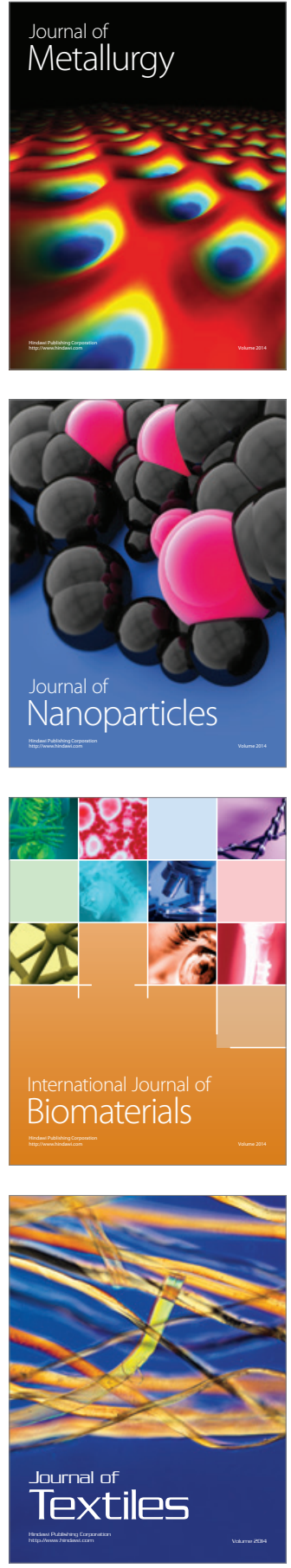